\title{
Modelling the Relationships between Personality Factors, Perceptions of the School as a Learning Organisation and Workplace Learning of School Teachers
}

\author{
*TENGKU FAEKAH TENGKU ARIFFIN \\ ROSNA AWANG HASHIM \\ KHULIDA KIRANA YAHYA \\ Universiti Utara Malaysia \\ *(faekah@uum.edu.my)
}

\begin{abstract}
Purpose - In this study, a structural model based on Kurt Lewin's Field Theory was proposed to explain how the interrelationships between a person (i.e. personality factors) and his or her environment (i.e. how one perceives the school as a learning organisation) can influence the person's behaviour. The outcome behaviour of interest in this study is the teacher's engagement in workplace learning activities.

Method - This is a a causal-comparative study which utilises a survey method for data collection. The sample involved a total of 400 school teachers who were selected through a multistage cluster analysis sampling procedure. The data analysis involved an adoption of the two-step procedure. The first step was the analysis of the overall measurement model, followed by the analysis of the proposed structural model through structural equation modelling (SEM).
\end{abstract}

Findings - Results indicated that three of five personality factors (conscientiousness, extraversion, and openness to experience) and how the teacher perceived the school as a learning organisation, are significant influences of teacher's engagement in workplace learning activities. Based on the holistic approach in model evaluation, both the overall measurement model and the structural model were found to be adequately fit.

Value - The study proposed a model which highlights the importance of personality factors and perceptions of the school as a learning organisation, and as significant contributors of workplace learning. 
Practical implications such as the improvement of personality items in the current teacher selection tool and the application of learning organisation in the school context are elaborated in this paper.

Keywords: workplace learning - personality ( $\left.{ }^{1} \mathrm{NEO}-\mathrm{FFI}-3\right)$ learning organisation - teachers

\section{INTRODUCTION}

Workplace learning has become an increasingly important concept underlying lifelong learning among workers. Authors of the workplace learning literature, such as, Engestrom (1999), and Lave and Wenger (1991) viewed formal education as an inadequate form of learning that only a limited number of working people are able to participate in. This notion is also true particularly in the case of teachers in Malaysia, because the allocated budget and opportunities for teachers to further their studies or to attend off-site training are very limited. This is an endemic situation, experienced by teachers and other workers in general - the need for learning exceeds the opportunity for formal learning. Thus, researchers began to seek for better ways of improving teachers' learning by steering away from the traditional concept of staff development, to a more participative nature of learning, which focuses more on the way workers are given the opportunity to learn through engaging in activities at their workplaces (Billett, 2001), or similarly, in communities of practice (Lave \& Wenger, 1991). By doing so, the researchers are not only looking into the individual learner, but also the social and cultural aspects of learning (Hodkinson \& Hodkinson, 2005).

The current research aims to look at how the interrelationships between the individual factors such as teacher personality factors, and the environmental factor, such as teachers' perceptions of the school as a learning organisation, can influence teachers' workplace learning behaviour. A model based on Kurt Lewin's Field Theory was proposed to explain the relationships between the personality factors (neuroticism, extraversion, openness to experience agreeableness,

\footnotetext{
${ }^{1}$ Adapted and reproduced by special permission of the Publisher, Psychological Assessment Resource, Inc., 16204 North Florida Avenue, Lutz, Florida 33549, from the NEO Five-Factor Inventory by Paul T. Costa Jr., PhD and Robert R. McCrae, PhD, Copyright 1978, 1985, 1989, 1991, 2003 by PAR, Inc.
} 
and conscientiousness), perceptions of the school as a learning organisation, and engagement in workplace learning activities.

\section{LITERATURE REVIEW}

The literature review is organised in a way that it will firstly discuss the theoretical background of this research, the Kurt Lewin's Theory. Then, the review elaborates on the concept of personality, learning organisation, and workplace learning. Next, the authors will gauge towards establishing the hypothesis which postulated how the relationships between the personality factors and perceptions of the school as a learning organisation influence engagement in workplace learning activities. These relationships are the ones that form the structural model which was tested via structural equation modelling (SEM).

\section{Kurt Lewin's Field Theory}

The Lewin's Field Theory is similar with the interactionist perspective because it attempts to explain the relationships between person and behaviour by looking at the possible role of the environmental factors. The reciprocal relationships between person and environment means that not only situational factors can influence a person to show his or her traits, but at the same time, a person's traits can influence how he views the situation.

A person's behaviour is influenced by the total interrelationships between the person himself and the psychological environment. This dynamic relationship between the person and his or her environment makes up what is termed as the field. This field is said to be dynamic because it endures through time and can adapt to the internal forces within and external forces that exist surrounding a person. The field is referred to the person's life space, which, to a certain extent, is governed by the person himself; however, in many situations, life space is largely determined by the environment and the people he is connected to. Applied to the current research, the theoretical assumptions proposed by Lewin can be useful to explain how teachers' personality (person) and the perceptions of the learning culture in the school (the psychological environment) can influence the teachers' behaviour in the workplace in terms of being engaged in learning activities in the workplace. 


\section{Personality}

The most prevalent concept of personality the big five factor or the five factor model which is said to be robust in nature. The big five dimensions are: 1) extraversion; 2) agreeableness; 3) conscientiousness; 4) neuroticism; and, 5) openness to experience.

Although different authors give slightly different operational definitions for each of the five factor dimensions of personality, the universal characteristics of each dimension is generally agreed upon. Individuals who score high on the personality factor of extraversion are usually seen as active, assertive, energetic, gregarious, sociable, and talkative (Barrick \& Mount, 1991; John \& Benet-Martinez, 2000).

Agreeableness is about being flexible, cooperative, caring, trustful, forgiving, and tolerant. An agreeable person is generally altruistic in nature (Costa \& McCrae, 1992). He or she is sympathetic to others, always eager to lend a helping hand, and believes that others would equally help them in return.

A person who scores high on the conscientiousness factor tends, to be achievement-oriented, careful, hardworking, orderly, persevering, responsible, and thorough (Barrick \& Mount, 1991; John \& Benet-Martinez, 2000). High conscientiousness scorers are also dependable, well-organised, well-disciplined, and demonstrate high levels of commitment (Costa \& McCrae,_1992; Stewart, 1999).

People who score high on neuroticism are prone to experience negative affects such as fear, anxiety, sadness, anger, guilt, embarrassment, and loneliness. They are vulnerable to stress because they tend to panic and feel that they are incapable of handling difficult situations. They also have poor control of their cravings and urges.

The last factor of personality, openness to experience is not only related to the intellectual aspect but also aesthetics, feelings, actions, and fantasy (Costa \& McCrae, 1992). Individuals who score high on openness often have creative imagination; they appreciate art and beauty; they are avid explorers of new experiences; and they can easily adapt to change because they are willing to consider unconventional ideas and values.

\section{Learning Organisation}

The learning organisation concept is chosen in order to gear this research toward a more specific kind of culture; that is, the learning 
culture. Learning organisation has its own set of environmental features that is worth considering because it was proven as having an impact on how people in the organisation generally behave. Generally, learning organisation is used to describe an organisation that is constantly adapting and improving itself through the culture of organisational learning and development (Senge, 1990, 2006; Marsick \& Watkins, 2003; Watkins \& Marsick, 1993).

The learning organisation model which was originally suggested for business and industries (Senge, 1990; Marsick \& Watkins, 2003; Watkins \& Marsick, 1993) was later proposed as a model that can also be applied in the educational or school context (Senge, 2000) for its benefits in improving school effectiveness and quality (Hallinger, 1998; Robinson, 2001). The concept of learning organisation was also suggested to be applied in the Malaysian educational context (Abdul Rahman, 2002).

Perceiving the school as a learning organisation in the context of this study actually referred to the perceptions of teachers as to whether or not the school posseses the characteristics of a learning organisation. The comprehensiveness of the learning organisation model as suggested by Marsick and Watkins (2003) and Watkins and Marsick (1993) is believed to be very informative and useful in delineating the organisational climate that exists in the school environment. There are seven dimensions of learning organisation as proposed by Watkins and Marsick (1993) and Marsick and Watkins (2003); namely i) continuous learning, ii) inquiry and dialogue, iii) team learning, iv) embedded system, v) empowerment, vi) building connection, and vii) leadership for learning.

\section{Workplace Learning}

Workplace learning is built upon two important key ideas; which are (i) workplace learning is ubiquitous, seen as an integral part of workplace practices (Lave \& Wenger, 1991; Engestrom, 1999; Billett, 2002), and (ii) workplace learning is part of the social and cultural process (Hodkinson \& Hodkinson, 2005). In the present study, workplace learning includes informal and formal learning activities. Taking a position similar to that of Billett (2001) and Beckett and Hager (2000), we rejected the notion of informal learning being inferior compared to learning in the formal educational context. In fact, it has been highlighted that only $20 \%$ of what employees learn comes from formalised, structured training, or education (Marsick \& Watkins, 1990). 
Similar to previous studies (Kwakman, 2003; Henze, 2009), workplace learning in the current study is examined by identifying the informal activities that teachers normally and intentionally engage in, either individually or in groups. Learning often occurs when teachers and workers in general, collaborate with others during courses or training (Hodkinson \& Hodkinson, 2005; Clarke, 2005), participate in group activities (Eraut, 2000; Cheetham \& Chivers, 2001; Hodkinson \& Hodkinson, 2005; Lohman, 2006), attend forums or meetings (Hodkinson \& Hodkinson, 2005; Clarke, 2005), observe others or role-models (Cheetham \& Chivers, 2001; Lohman, 2006; Clarke, 2005), work alongside experienced colleagues (Cheetham \& Chivers, 2001), read and experiment (Lohman, 2006; Clarke, 2005), share resources (Lohman, 2006), tackle challenging or new tasks (Hodkinson \& Hodkinson, 2005; Eraut, 2000), and mentor, teach, or train others (Cheetham \& Chivers, 2001).

\section{Model Development and Hypothesis Formulation}

There are not many studies that identified individual factors or specifically, personality factors, which influence a teacher's engagement in workplace learning activities. The lack of such studies may be due to the assumption that knowledge about the characteristics or personality of people in the workplaces cannot be of valuable information to an organisation. To a certain extent, adult personality traits are believed to be unchangeable. This opinion can still be disputed because it was proven that characteristics or personality of individuals can indeed be influenced by the context they are in (Jawahar \& Carr, 2007; Tett \& Burnett, 2003).

Hodkinson and Hodkinson $(2004,2005)$ found that teachers' dispositions, particularly their experience, prior knowledge, and skills, are related to the way teachers learn or take advantage of learning opportunities available in their workplaces. In addition, Lohman $(2000,2003)$ in her qualitative studies on teacher's workplace learning involvement, identified four individual characteristics which are important in enhancing teacher's engagement in an informal workplace learning. These characteristics are initiative, self efficacy, commitment to lifelong learning, and love of content area. In order to generalise these findings, Lohman (2006) carried out a quantitative research and found that these personal characteristics (initiative, self-efficacy, love of learning, and interest in profession) exert influence on teacher's participation in informal workplace 
learning activities. These findings supported propositions made by Doornbos, Bolhuis, and Simons (2004) when they suggested that worker's social integration experience (in other words, sociability), and perceived value of learning at work determine intentionality of work-related learning.

To a certain extent, individuals who have initiative and are committed, are generally conscientiousness people (although the converse may not be true; those who are conscientious may not necessarily have initiative, and/or committed as well). In addition, those who are sociable have the essence of being extraverts. This is because sociability is one of the indicators of extraversion. Naquin and Holton (2002) found that conscientiousness and agreeableness are valid predictors of motivation to improve work through learning, mediated by work commitment. In addition, conscientiousness, extraversion, openness, and agreeableness are valid predictors of positive work behaviour (job performance) (Barrick \& Mount, 1991; Barrick, Mount, \& Judge, 2001). Given these findings, it was hypothesised that the following factors of extraversion, agreeableness, openness to experience, neuroticism, and conscientiousness are also valid predictors of yet another positive work behaviour, which is engagement in workplace learning.

$\begin{aligned} & \mathrm{H}_{1 \mathrm{a}}: \begin{array}{l}\text { Teacher personality factor of extraversion } \\ \text { positively influences teacher engagement in }\end{array} \\ & \mathrm{H}_{1 \mathrm{~b}}: \begin{array}{l}\text { Teacher personality factor of agreeableness } \\ \text { positively influences teacher engagement in }\end{array} \\ & \begin{array}{l}\text { workplace learning activities. } \\ \mathrm{H}_{1 \mathrm{c}}:\end{array} \\ & \begin{array}{l}\text { Teacher personality factor of conscientiousness } \\ \text { positively influences teacher engagement in }\end{array} \\ & \text { workplace learning activities. } \\ & \mathrm{H}_{1 \mathrm{~d}}: \begin{array}{l}\text { Teacher personality factor of neuroticism } \\ \text { negatively influences teacher engagement in } \\ \text { workplace learning activities. }\end{array} \\ & \mathrm{H}_{1 \mathrm{e}}: \text { Teacher personality factor of openness to } \\ & \text { experience positively influences teacher } \\ & \text { engagement in workplace learning activities. }\end{aligned}$

With regard to perceived organisational factors, researchers have examined some of those that are found to relate to workplace learning. To some extent, these factors share similar concepts, but are labelled differently. Based on previous studies, perceptions of the 
workers of the learning conditions (Skule, 2004), characteristics of a learning organisation (Marsick \& Watkins, 2003), learning factors (Eraut, 2000), workplace environment and learning support (Clarke, 2005), and learning opportunities or affordances (Billet, 2001), are all important for determining the workers' learning behaviour in their workplaces. In the school context, the organisational factors which were found to have relationships with teacher's participation in workplace learning are, job condition and proximity to colleague's work area (Lohman, 2006); system recognition and reward, resources, and support (Retallick \& Groundwater Smith, 1999), and departmental culture (Hodkinson \& Hodkinson, 2004).

Review on the school culture (Maslowski, 2006) and school climate (Hoy, Hoffman, Sabo, \& Bliss, 1996) found that the aspects that are usually included in the measurement of these constructs are teacher collegiality and teamwork, principal leadership, teacher autonomy, networking at all levels, and teacher professionalism. Most of these dimensions of school culture are similar to that of the dimensions of learning organisation as proposed by Watkins and Marsick (1993). Previous studies had established the fact that school culture (Day, 1999; Harris, 2001), collaborative culture (Hargreaves, 1992), norm of continuous school improvement, norm of teamwork, and norm of valuing teacher competency (Gaziel, 2001) are also important factors in explaining teacher development activities. Therefore, it was postulated in the present research that teacher's perception of school learning culture will influence his or her development activities, including effort in upgrading knowledge and skills, via learning in the workplace.

$$
\begin{aligned}
& \mathrm{H}_{2} \text { : Teacher's perceptions of school as a learning } \\
& \text { organisation positively influence teacher's } \\
& \text { engagement in workplace learning activities. }
\end{aligned}
$$

The structural model that was proposed and tested in this study addressed all the above-mentioned hypotheses.

\section{METHODOLOGY}

\section{Reserch Design}

This was a causal-comparative study which utilised a survey method for data collection. It involved the gathering of cross-sectional data to investigate the roles of personality and perceived school as learning organisation, on teacher's workplace learning. 


\section{Sampling}

The target population for the study was the secondary school teachers in the state of Kedah. Based on the total number of secondary school teachers in Kedah, which is approximately 9554 (Kedah State Department of Education), and according to Krejcie and Morgan's (1970) sample size calculation, with the confidence level of $95 \%$, the estimated number of respondents needed for this study was approximately 370 teachers. Since getting the population frame of all teachers in the state was difficult and not feasible, it was decided that a multistage mixed sampling method be used to determine the accessible population, and then the subjects needed for this study. Multistage sampling is used as an extension of the concept underlying cluster sampling (Henry, 1990).

\section{Instrumentation}

The questionnaire comprised 98 items and was divided into four sections. The first section measures teacher personality (60 items) of the NEO-FFI-3 (Costa \& McCrae, 1992). Sample items included, "I try to be courteous to everyone I meet", "I have a clear set of goals", and "I am seldom sad or depressed".

The second section, perceptions of the school as a learning organisation (21 items), was adapted from the short version of the Dimensions of Learning Organisation Questionnaire (DLOQ) by Marsick and Watkins (2003). The instrument was adapted to measure the perceptions of teachers toward the school as having (or not having) the environment for learning. The learning environment is embedded within the people, system, and structure of the school. The DLOQ measures a multidimensional (seven-dimensions) construct of the learning organisation. Sample items are, "In my school, the teachers help each other learn to do their job better", and "In my school, teams of teachers make certain decisions as a result of group discussions or collective thinking".

The final construct measured was the teacher's engagement in workplace learning activities (11 items). The majority of the items (eight items) were adapted from Lohman's (2006) quantitative study, whereas the remaining three items were constructed based on several other studies on teacher's workplace learning (Clarke, 2005; Hodkinson \& Hodkinson, 2005; Cheetham \& Chivers, 2001; Eraut, 2000). Sample items are, "I put effort on learning how to do 
my job better by reading professional book, magazines or journals", and "I put effort on learning how to do my job better by working alongside my colleagues". All items (except for demographics) were measured using a five-point Likert scale type of response, ranging from "strongly disagree" to "strongly agree".

\section{Analysis}

Item parcels were used instead of individual items in the analysis. Use of item parceling in SEM is a common practice (Bandalos, 2002; Bandalos \& Finney, 2001) because it results in fewer parameter estimations which then create a more optimal variable to sample size ratio (Bogazzi \& Edwards, 1998). The items for each personality factor were randomly bundled into three four-item parcels. Several authors such as Little, Cuningham, Shahar, and Widaman, (2002), and Bryne (2005) have suggested the use of random assignment of items as a method of parcelling. A similar item parcelling technique (assigning four items at random per parcel) for NEO-FFI personality items was also conducted in a recent study by Feldt, Metsapelto, Kinnunen, and Pulkkinen (2007).

The items for perceived school as learning organisation were bundled into seven three-item parcels, each of which representing the composite score of each facet or dimension. This parcelling technique was appropriate for use with a multidimensional construct, whereby the internally consistent facets in the lower order were manifested as indicators of the higher order latent construct (Kishton \& Widaman, 1994). Using the same item-parceling technique, the items for workplace learning were bundled into two two-item parcels (for group learning), and two two-item and one three-item parcel (for individual learning). This resulted in 27 item parcels or also known as indicators, which were more manageable and reduced problems in convergence (Little, et al., 2002).

\section{RESULTS}

\section{Profile of Respondents}

The profile of respondents is shown in Table 1. Out of 366 respondents, $68.3 \%$ are female $(\mathrm{n}=250)$ and $31.7 \%$ are male $(\mathrm{n}=116)$. The majority of them, $83.1 \%(\mathrm{n}=304)$ had a Bachelor's Degree as the highest education attainment. There were also a small 
number of teachers, $9.3 \%(n=34)$, with a Diploma, and $7.7 \%(n=$ 28 ) with a Master's Degree. In terms of age, more than $80 \%$ of the respondents were 31-50 years. It was also noted that the majority of respondents had more than 10 years of teaching experience $(76.0 \%$, $\mathrm{n}=278)$, leaving the remaining $24 \%(\mathrm{n}=88)$ of the respondents having less than 10 years of experience. The mean age and teaching experience of the sample were $40.7(\mathrm{SD}=6.6)$ years and $15.3(\mathrm{SD}=$ 7.4) years respectively.

\section{Table 1}

Respondent's Profile by Gender, Education level, Subject Taught, Age and Teaching experience

\begin{tabular}{llcc}
\hline Category & $\begin{array}{c}\text { Number of } \\
\text { respondents }\end{array}$ & $\begin{array}{c}\text { Percentage } \\
(\%)\end{array}$ \\
\hline Gender & Female & 250 & 68.3 \\
& Male & 116 & 31.7 \\
& Total & 366 & 100 \\
Highest academic & Diploma & 34 & 9.3 \\
attainment & Bachelor Degree & 304 & 83.0 \\
& Master Degree & 28 & 7.7 \\
& Total & 366 & 100 \\
Age & Less than 30 years & 30 & 8.2 \\
& 31-40 years & 153 & 41.8 \\
& 41-50 years & 157 & 42.9 \\
& More than 50 years & 26 & 7.1 \\
Teaching & Total & 366 & 100 \\
experience & 1-10 years & & \\
& More than 10 years & 278 & 24.0 \\
& Total & 366 & 76.0 \\
& & $($ Mean $=15.3)$ & $\underline{(S D}=7.4)$ \\
\hline
\end{tabular}

\section{The Measurement Model}

In SEM, it is recommended that a two-step approach be adopted (Anderson \& Gerbing, 1988) - the analysis of the measurement model through confirmatory factor analysis (CFA), followed by the analysis of the structural model.

In this article, it is the findings of overall measurement model that is reported, rather than the single measurement models. The 
purpose of testing the overall measurement model is two-fold, namely i) to establish the convergent validity of each construct, and concurrently, ii) to observe the discriminant validity between the constructs. In order to test for the model fitness, the overall measurement model was firstly specified as a simple model. The model specifications followed the guidelines on the characteristics of a standard CFA model (Bryne, 2005; Kline, 2005). The general specifications of a simple measurement model in the present study were, 1) each indicator was a continuous variable which comprises a single non-zero loading on the underlying targeted factor, and an error term; 2) the error terms were independent of each other and the factor; and 3) all associations between the measured variables (indicators) were not analysed. In addition, one of the loading paths from a set of measure which was postulated to assess the same construct was constrained to a value of 1.00. This was for the purpose of model identification. Once the specification and identification of the measurement model were established, the model was evaluated for goodness of fit and its parameters were estimated via maximum likelihood procedure.

Following a holistic approach to model evaluation, this overall measurement model was tested for the overall fitness by referring to several fit indeces as suggested by Brown (2006) and Bryne (2005). The fit indeces referred to were the Tucker-Lewis index (TLI), Tucker \& Lewis, 1978), the comparative fit index (CFI) (Bentler, 1990), the standardised root mean residual (SRMR) (Hu \& Bentler, 1999) and the root mean square error of approximation (RMSEA) (Steiger, 1990) along with its 90\% confidence interval (CI). While the $X^{2}$ value is still reported, as in many applied research, it is rarely used for the evaluation of model fit. The reason is because the $X^{2}-$ statistics are based on a very stringent hypothesis that assumes that the model fits perfectly in the population. Furthermore, it has been proven that the $X^{2}$-statistics are also sensitive to large sample size, which results in the value of $\mathrm{p}<.05$ (even if the postulated model is actually a good model) (Brown, 2006; Bryne, 2009).

With regard to the cut-off values of the fit indexes, values of more than .90 for CFI and TLI (Bentler, 1990; Bentler \& Bonnet, 1980; Bryne, 2005); less than .08 for SRMR (Hu \& Bentler, 1999); and less than .08 for RMSEA (Brown \& Cudeck, 1993; McCallum, Brown, \& Suguwara, 1996) indicated that the model adequately fits. Besides that, the goodness of individual parameters were checked by ensuring that there was no negative variance or correlations $(>1.0)$, and the significance of the parameters estimated $(\mathrm{t}>1.96, \mathrm{p}<.05)$. 
The postulated overall measurement model was such, that 1) the responses to the personality, perceptions of the school as a learning organisation and engagement in workplace learning activities were explained by nine latent constructs (five personality constructs, one construct of perceptions of the school as a learning organisation, and three constructs of the second-order workplace learning model); and these constructs were all correlated;2) there were altogether 27 indicators or item parcels (each personality factor had three item parcels, perceptions of the school as a learning organisation had seven item parcels, and workplace learning five item parcels); 3) each indicator had a non-zero loading on the targeted factor and zero loadings on other factors; and 4) the error terms were uncorrelated. All 27 item parcels were subjected to confirmatory factor analysis via AMOS 16.0 (Arbuckle, 2008).

The results indicated that the model had acceptably fit with TLI $=.90$, CFI=.92, RMSEA $=.066(\mathrm{CI}=.055-.077), \mathrm{RMR}=.016$, and $X^{2} / \mathrm{df}=2.10\left(X^{2}=632.98, \mathrm{df}=301, \mathrm{p}=.000\right)$. The factor loadings ranged from $\beta=.50, t=6.48$ to $\beta=.92, t=17.17$, and were significant at $\mathrm{p}<.05$; hence, convergent validity was established for this overall measurement model. Disattenuated correlations between the latent constructs were less than $r=.90$ (ranging from $r=.01$ to $r=.59$ ), lending evidence for discriminant validity (John \& Benet-Martinez, 2000).

\section{Test of Hypotheses and the Structural Equation Model}

Following CFA for the measurement model, the theoretical model and hypotheses were then tested for fitness with the data. Figure 1 shows the nomological network or the hypothesised structural model with the relevant parameter estimates. The summary of fit indices (TLI=.90, CFI=.92, $\mathrm{RMSEA}=.05$, and $\mathrm{X}^{2} / \mathrm{df}=2.10$ ) indicated that an adequately fitting model was established. In addition, the path coefficient estimates were all significant $(\mathrm{p}<0.05)$. There was a statistically significant link between three of five personality factors (extraversion, $\beta=.26, t=2.18$; conscientiousness, $\beta=.30$, $t=3.70$; and openness to experience, $\beta=.23, t=4.73$ ) and workplace learning; thus, providing support for Hypothesis 1a, 1c, and 1e.

With regard to the link between perceptions of the school as a learning organisation and workplace learning, the analysis showed that there was also a significant link between them $(\beta=0.29, t=4.73)$, lending support for Hypothesis 2. The total variance explaining engagement in workplace learning activities, by personality factors 
and perceptions of school learning as organisation, was $56 \%$. Figure 1 illustrates the simplified version of the structural model with standardised values for the parameters estimated.
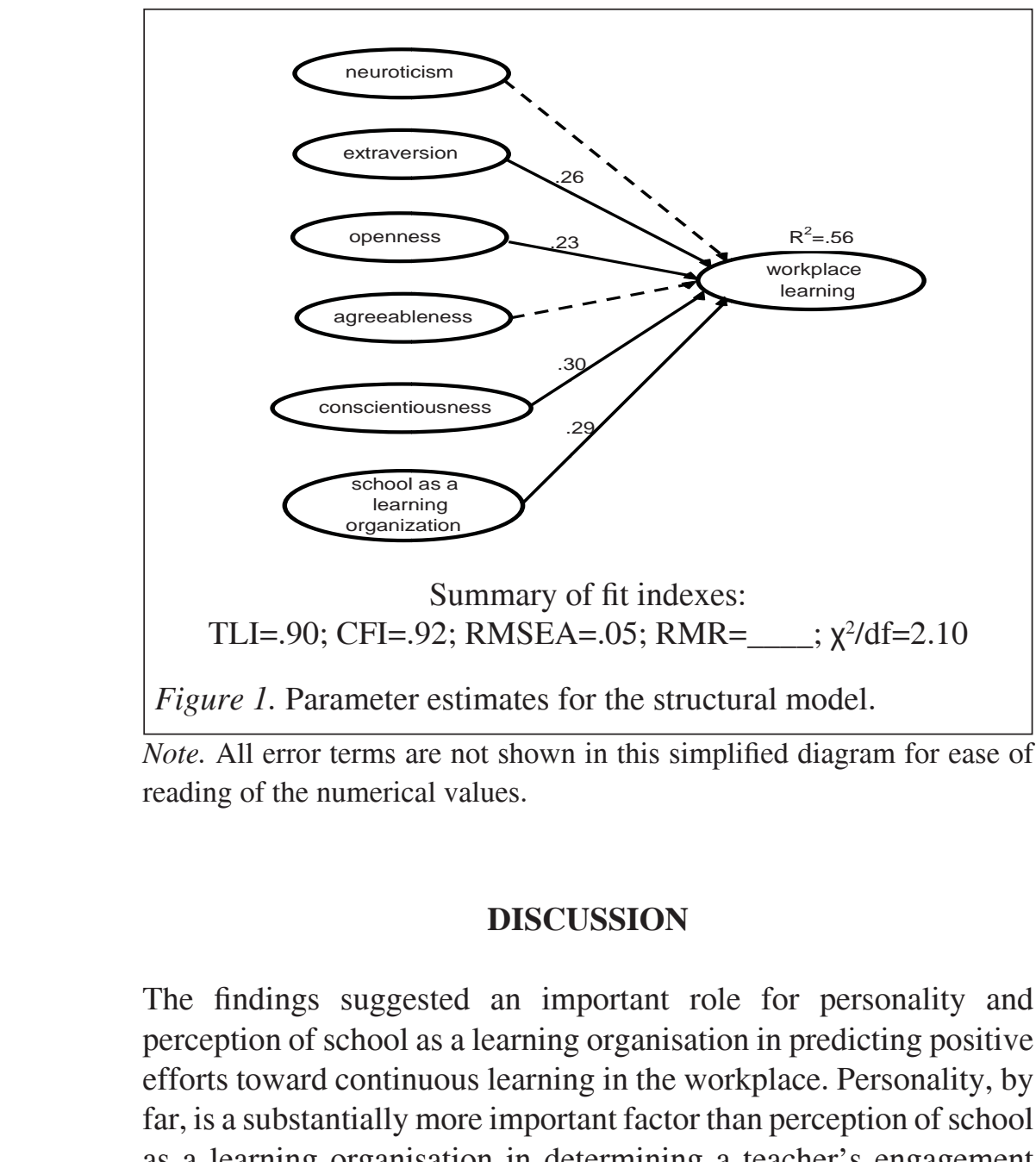

Note. All error terms are not shown in this simplified diagram for ease of reading of the numerical values.

\section{DISCUSSION}

The findings suggested an important role for personality and perception of school as a learning organisation in predicting positive efforts toward continuous learning in the workplace. Personality, by far, is a substantially more important factor than perception of school as a learning organisation in determining a teacher's engagement in workplace learning activities. In this study, the personality domain was presented as being made up of five factors: neuroticism, extraversion, agreeableness, conscientiousness, and openness; factors which have been repeatedly found to be significant predictors of workplace behaviour such as performance (Barrick \& Mount, 1991; Barrick, et al., 2001). The research presented here provides further evidence for the relevance of these personality factors in 
explaining engagement in workplace learning when three out of five of the personality factors were found to be significant predictors of engagement in workplace learning activities. Simultaneously, it provides evidence for previous findings concerning the relationships between teacher individual dispositions such as initiative and commitment (somewhat similar to conscientiousness) and sociability (similar to extraversion), and workplace learning (Hodkinson \& Hodkinson, 2005; Lohman, 2003, 2006).

Teachers who score high on the personality factor of conscientiousness are diligent, well-organised, responsible, reliable, thorough, achievement-oriented and persevering. These are characteristics of well-performing teachers. The teaching job requires a teacher to be responsible for their students' learning. As such, teachers would also regard workplace learning as part of their duty in order to improve their teaching, thus achieving the targets that they have set for their students. As for the personality of extraversion, the findings indicated that a teacher who is an extravert tends to be more engaged with workplace learning activities. An extravert may find it easier to solicit information from his or her colleagues. In that sense, learning became a lot more of a social activity for extraverts.

Another personality factor which was also found to influence teachers' engagement in workplace learning activities is openness to knowledge and experience. One who is more open usually finds it easier to absorb whatever information and situation he or she is in, without being overly careful or sceptical. The current study denotes that the same applies in the case of a teacher. Teachers with an open personality rated themselves as being more engaged with workplace learning activities. Teachers who rate themselves as open individuals are people who are ready to learn new things, listen to others, appreciate people's opinions of certain things and are generally more creative in nature. In carrying out the job as teachers, there are always changes, for example changes in the curriculum. Being more open means that teachers are able to learn the new things, and adapt themselves to these changes more easily. Teachers who are more creative and more sensitive are seen as more advantageous because the teaching job requires teachers to deal with different matters everyday - thus, they need to continuously learn to be able to tackle new challenges.

A teacher's perception of school as a learning organisation is also a significant contributor to their involvement in workplace 
learning. In the context of this research, the school is perceived as a learning organisation if the teachers believe that it emphasises continuous learning effort, encourages inquiry and dialogues, promotes networking within and beyond the school members, develops an embedded system that supports workplace learning, and also supports team learning and collaborative culture (Marsick \& Watkins, 2003; Watkins \& Marsick, 1993). In addition, teachers should also perceive that the school leader practices empowerment, encourages knowledge sharing and supports workplace learning and lifelong learning. The extent to which teachers perceive whether or not the school possesses the above elements of a learning organisation plays a significant role in determining a teacher's continuous learning in the workplace.

\section{CONCLUSION}

Teachers need to continuously upgrade their knowledge and skills to keep themselves updated with the latest educational developments in pedagogical approaches and educational technology. This study has contributed to the body of knowledge previous research in that it highlights that a teacher's personality traits and his/her perceptions of the school as a learning organisation are important factors that can contribute toward a teacher's workplace learning. Therefore, teacher personality traits should be given increased attention, be it in screening potential candidates for teacher training programmmes or in recruiting already trained in-service teachers. However, personality tests should not be used as the sole means for predicting future workplace behaviour of teachers or workers in general because there is the risk of dishonesty in providing personality profiles due to the social desirability factor.

With regard to organisational factors, rather than focusing solely on tangible factors such as monetary rewards, a school that is perceived as a learning organisation by teachers has an impact on whether or not the teachers will be actively engaged in workplace learning. To summarise, good teachers are those who will engage in continuous learning throughout their careers so as to continually improve their workplace performance. Both teacher's personality and their perceptions of their school as a learning organisation are important substantial for generating positive workplace behaviour such as workplace learning or lifelong learning. 


\section{REFERENCES}

Abdul Rahman Ahmad (2002). The building of a learning organisation: A requirement for educational organizations. In Sufean Hussin (Ed.), Revitalising education (pp. 84-199). Kuala Lumpur: Utusan Publications \& Distributors Sdn. Bhd. Anderson, J. C., \& Gerbing, D. W. (1984). The effects of sampling error on convergence, improper solutions and goodness-of-fit indices for maximum likelihood confirmatory factor analysis. Psychometrika, 49, 155-173.

Arbuckle, J. L. (2008). AMOS (version 16.0) [Computer software]. Chicago: Smallwaters.

Bandalos, D. L. (2002). The effects of item parcelling on goodnessof-fit and parameter estimate bias in structural equation modeling. Structural Equation Modeling, 9, 78-102.

Bandalos, D. L., \& Finney, S. J. (2001). Item parcelling issues in structural equation modeling. In G. A. Marcoulides, \& R. E. Schumacker (Eds.), Advanced structural equation modeling: New developments and techniques. Mahwah, NJ: Lawrence Erlbaum Associates, Inc.

Barrick, M. R., \& Mount, M. K. (1991). The big five personality dimensions and job performance: A meta analysis. Personnel Psychology, 44, 1-26.

Barrick, M. R., Mount, M. K., \& Judge, T. A. (2001). Personality and performance in the new millenium: What do we know and where do we go next? Personality and Performance, 9, 9-29.

Beckett, D., \& Hager, P. (2000). Making judgments as the basis for workplace learning: Towards an epistemology of practice. International Journal of Lifelong Education, 19, 300-311.

Bentler, P. M. (1990). Comparative fit indexes in structural models. Psychological Bulletin, 107 238-246.

Bentler, P. M., \& Bonett, D. G. (1980). Significance tests and goodness of fit in the analysis of covariance structures. Psychological Bulletin, 88, 588-606.

Billett, S. (2001). Learning through work: Workplace affordances and individual engagement. Journal of Workplace Learning, $13,209-214$.

Billett, S. (2002). Critiquing workplace learning discourses: Participation and continuity at work. Studies in Education of Adults, 34, 56-67.

Bogazzi, R. P., \& Edwards, J.R. (1998). A general approach to construct validation in organisational psychology: Application to the measurement of work values. Organisational Research Methods, 1, 45-87. 
Brown, M. W., \& Cudeck, R. (1993). Alternative ways of assessing model fit. In K. A. Bollen, \& J. S. Long (Eds.), Testing structural equation models (pp. 136-162). Beverly Hills, CA: Sage.

Brown, T. A. (2006). Confirmatory factor analysis for applied research. New York: The Guilford Press.

Bryne, B. (2005). Factor analytic models: Viewing structure of an assessment instrument from three different perspectives. Journal of Personality Assessment, 85, 17-32.

Bryne, B. (2009). Structural equation modeling with AMOS: Basic concepts, applications, and programming (2nd ed.). New York: Routledge.

Cheetham, G., \& Chivers, G. (2001). How professionals learn in practice: An investigation of informal learning amongst people working in professions. Journal of European Industrial Training, 25, 248-292.

Clarke, N. (2005). Workplace learning environment and its relationship with learning outcomes in healthcare organisations. Human Resource Development International, $8,185-205$.

Costa, P. T. J., \& McCrae, R. R. (1992). Revised NEO Personality Inventory (NEO-P-I-R) and NEO Five-Factor Inventory (NEOFFI) professional manual. Odessa, Florida: Psychological Assessment Resources, Inc.

Day, C. (1999). Developing teachers: The challenge of lifelong learning. London: Falmer Press.

Doornbos, A. J., Bolhuis, S., \& Simons, P. R. (2004). Modeling work-related learning on the basis of intentionality and developmental relatedness: non-educational perspective. Human Resource Development Review, 3, 250-274.

Engestrom, Y. (1999). Activity theory and individual and social transformation. In Y. Engestrom, R. Miettinen, \& R. Punamaki (Eds.), Perspectives on activity theory. Cambridge: Cambridge University Press.

Eraut, M. (2000). Non-formal learning and tacit knowledge in professional work. British Journal of Educational Psychology, 70, 113-136.

Feldt, T., Metsapelto, R., Kinnunen, U. \& Pulkkinen, L. (2007). Sense of coherence and five-factor approach to personality conceptual relationships. European Psychologist, 12, 165-172.

Gaziel, H. H. (2001). Impact of school culture on effectiveness of secondary schools with disadvantaged students. The Journal of Educational Research, 90, 310-318. 
Hallinger, P. (1998). Educational change in the Asia-Pacific region: The challenge of system. Journal of Educational Administration, 36, 492-509.

Hargreaves, A. (1992). Teacher development and educational change. London: Falmer Press.

Harris, A. (2001). Department improvement and school improvement: A missing link. British Educational Research Journal, 27, 477-486.

Henry, G. T. (1990). Practical sampling. Newbury Park, California: SAGE Publications, Inc.

Henze, I. (2009). Experienced science teachers' learning in the context of educational innovation. Journal of teacher education, 60, 184-199.

Hodkinson, H., \& Hodkinson, P. (2005). Improving school teachers' workplace learning. Research Papers in Education, 20, 109 - 131.

Hodkinson, P., \& Hodkinson, H. (2004). The significance of individuals disposition in workplace learning: A case study of two teachers. Journal of Education and Work, 17, 167-182.

Hoy, W. K., Hoffman, J., Sabo, D., \& Bliss, J. (1996). The organisational climate of middle schools. Journal of Educational Administration, 34, 41-59.

Hu, L., \& Bentler, P. M. (1999). Cutoff criteria for fit indexes in covariance structure analysis: Conventional criteria versus new alternatives. Structural Equation Modeling, 6, 1-55.

Jawahar, I. M., \& Carr, D. (2007). Conscientiousness and contextual performance: The compensatory effects of perceived organisational support and leader-member exchange. Journal of Managerial Psychology, 22, 330-349.

John, O. P, \& Benet-Martinez, V. (2000). Measurement: Reliability, construct validation and scale construction. In H. T. Reis, \& C.M. Judd (Eds.). Handbook of research methods in social and psychological personality (pp. 339-369).

Kline, R. B. (2005). Principles and practice in structural equation modeling (2nd ed.). New York: The Guilford Press.

Kishton, J. M., \& Widaman, K. F. (1994). Unidimensional versus domain representative parceling of questionnaire items: An empirical example. Educational and Psychological Measurement, 54, 757-765.

Kwakman, K. (2003). Factors affecting teachers' participation in professional learning activities. Teaching and Teacher Education, 19, 149-170.

Lave, J., \& Wenger, E. (1991). Situated learning. Cambridge: Cambridge University Press. 
Little, T. D., Cunningham, W. A., Shahar, G., \& Widaman, K. F. (2002). To parcel or not to parcel: Exploring the questions, weighing the merits. Structural Equation Modeling, 9, 151-173.

Lohman, M. C. (2000). Environmental inhibitors to informal learning in the workplace: A case study of public school teachers. Adult Education Quarterly, 50, 83-102.

Lohman, M. C. (2003). Work situations triggering participation in informal learning in the workplace: A case study of public school teachers. Performance Improvement Quarterly, 16, 40-54.

Lohman, M. C. (2006). Factors influencing teachers' engagement in informal learning activities. Journal of Workplace Learning, 18, 141-156.

Marsick, V. J., \& Watkins, K. E. (1990). Informal and incidental learning in the workplace. London: Routledge.

Marsick, V. J., \& Watkins, K. E. (2003). Demonstrating the value of an organization's learning culture: The dimensions of the learning organisation's questionnaire. Advances in Developing Human Resources, 5, 132-151.

Maslowski, R. (2006). A review of inventories for diagnosing school culture. Journal of Educational Administration, 44, 6-35.

McCallum, R. C., Brown, M. W., \& Suguwara, H. M. (1996). Power analysis and determination of sample size for covariance structural modeling. Psychological Methods, 1, 130-149.

Naquin, S. S., \& Holton III, E. F. (2002). The effects of personality, affectivity, and work commitment on motivation to improve work through learning. Human Resource development Quarterly, 13, 357-376.

Retallick, J., \& Groundwater-Smith, S. (1999). Teachers' workplace learning and the learning portfolio. Asia-Pacific Journal of Teacher Education, 27, 47-59.

Robinson, V.M.J. (2001). Descriptive and normative research on organizational learning: locating the contribution of Argyris and Schon. The International Journal of Educational Management, 15, 58-67.

Senge, P. M. (1990). The leader's new work: Building learning organizations. Sloan Management Review, 32, 7-23.

Senge, P. M. (2006). The fifth discipline: The art and practice of the learning organization. New York: Doubleday Publishing.

Skule, S. (2004). Learning conditions at work: A framework to understand and assess informal learning in the workplace. International Journal of Training and Development, 8, 8-20. 
Steiger, J. H. (1990). Structural model evaluation and modification: An interval estimation approach. Multivariate Behavioral Research, 25, 173-180.

Stewart, G. L. (1999). Trait bandwidth and stages of job performance: Assessing differential effects for conscientiousness and its subtraits. Journal of Applied Psychology, 84, 959-968.

Tett, R. P., \& Burnett, D. D. (2003). A personality trait-based interactionist model of job performance. Journal of Applied Psychology, 88, 500-517.

Tucker, L. R., \& Lewis, C. (1973). A reliability coefficient for maximum likelihood factor analysis. Psyhometrika, 38, 1-10.

Watkins, K. E., \& Marsick, V. J. (1993). Sculpting the learning organization: Lessons in the art and science of systemic change. San Francisco: Jossey-Bass Publishers. 